\title{
Augmented Cognition Methods for Evaluating Serious Game Based Insider Cyber Threat Detection Training
}

\author{
Terence S. Andre ${ }^{1}$, Cali M. Fidopiastis ${ }^{2}$, Tiffany R. Ripley ${ }^{1}$, \\ Anna L. Oskorus ${ }^{1}$, Ryan E. Meyer ${ }^{1}$, and Robert A. Snyder ${ }^{1}$ \\ ${ }^{1}$ TiER1 Performance Solutions

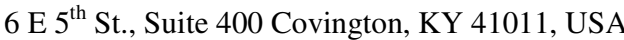 \\ ${ }^{2}$ University of Alabama-Birmingham \\ 1530 3rd Avenue South, Birmingham, Alabama 35294, USA \\ $\{t$.andre, t.ripley, a.oskorus, r.meyer, \\ r.snyder\}@tier1performance.com, cfidopia@uab.edu
}

\begin{abstract}
DoD investments into cyber threat defense are ongoing; however, little attention is paid to training personnel to detect and prevent threats to cyber networks that come from internal sources. Supervisors need to know what behavioral signs to watch for that might indicate an employee intends to commit an insider crime. Monitoring employee workstations is proving an ineffective means of determining insider threats. Training is needed to provide examples of the numerous ways cyber threats are achieved. An interactive roleplay game environment may provide an appropriate instructional delivery system to train supervisors. Such a training system should employ instructional support features, aids, and feedback to the trainer and the trainee. The training system should also provide adaptive learning pathways to facilitate accelerated learning where individual assessments show mastery of specific content. Creating such a system not only requires appropriate training materials, but also a means to assess the systems efficacy. Augmented cognition methods and techniques for evaluating the cognitive state of a learner provide a real-time, objective means of evaluating training delivery and content. In this paper we discuss our efforts to assess learner engagement using psychophysiological measures.
\end{abstract}

Keywords: accelerated learning; adaptive training; learner engagement, psychophysical measures.

\section{Introduction}

Accelerated learning remains a major, yet unattained, goal of education systems [1], government [2] [3], business [4] and the military [5]. In the military, in fact, the need "to dramatically accelerate the transition from novice to expert in key military tasks" is seen as absolutely crucial to the continued effectiveness of U.S. fighting forces around the globe [6]. On the educational front, in a system that requires $25-75 \%$ fewer school days than most other countries do, rapid increases in learning rate might prove to be the only factor that can offset the U.S.'s continued decline in science and math 
test scores in comparison with those of other nations. Thus, for many reasons, technological applications that substantially and reliably accelerate learning would have near unlimited market demand and potentially great social impact. The greatest social impact for accelerated learning may be upon us in the area of cyber security. The growing reliance on technological infrastructures has made organizations increasingly vulnerable to cyber attacks, especially those from inside the organization [7]. Effective training of key personnel is needed so that organizations have proactive measures in place to detect and prevent intrusions before breaches can do significant damage. Accelerated learning, implemented through customized learning pathways and interactive role-playing games may be the right approach to effectively train cyber network supervisors so they can detect behavioral warning signs of an insider threat.

Scenario-based, role-playing games are believed to increase student engagement [8]. However, measures of engagement are typically subjective. Psychophysiological measurements such as EEG and eye-tracking sensors have led to significant advances in scientists' understanding of the kind of learning retained [9] [10] [11]. Through accelerated learning approaches and innovative ways to measure learner engagement, we expect to establish new guidelines for learning applications, just as one might use a user-in-the-loop iterative strategy when designing adaptive training systems [12].

\section{Accelerated Learning}

Most managers have a goal of getting employees' knowledge and skills up to speed as quickly as possible and then maintaining their knowledge and skills over time. Effective organizational performance is often correlated with employee knowledge and skill. The issue of speed is especially important in cyber security training as the magnitude of the overall threats and the frequency of attacks continues to grow. Thus, there is increasing pressure on organizations to train their employees both faster and better in order to reduce "time to value" [13]. The most common name for this highly desired and valuable goal is accelerated learning.

Educational technology appears to have the greatest potential effect on learning speed through courseware that provides adaptive (thereby accelerated) learning [14]. In addition, scenario-based, role-playing games appear to be effective for those with higher levels of knowledge or skills at the outset and increase student engagement for all learners [15].

\subsection{TiER1 Approach to Accelerated Learning}

Definitions of accelerated learning typically differ depending upon the specific context in which the definition is used. A broad spectrum of accelerated learning definitions is represented in Table 1.

Working from the base of these varying perspectives, TiER1 has operationally characterized accelerated learning as the reduction of learner time required to meet learning objectives in a training event. 
Table 1. Definitions of Accelerated Learning

\begin{tabular}{|l|l|}
\hline \multicolumn{1}{|c|}{ Definitions of Accelerated Learning } & \multicolumn{1}{|c|}{ Authors } \\
\hline $\begin{array}{l}\text { Paraconscious mental activity that can create conditions } \\
\text { to automate and use memory, brain, and intellectual } \\
\text { reserves of people effectively }\end{array}$ & Lozanov (1978) [16] \\
\hline Providing effective training in a short period of time & Gill and Meier (1989) [17] \\
\hline Making a superlink between the right and left brain & Linksman (1996) [18] \\
\hline Adapting and learning new skills quickly & $\begin{array}{l}\text { Lawlor and Handley (1996) } \\
\text { [19] }\end{array}$ \\
\hline $\begin{array}{l}\text { The ability to absorb and understand new information } \\
\text { quickly and retain information }\end{array}$ & Rose and Nicholl (1997) [20] \\
\hline Changing behavior with increasing speed & Russell (1999) [21] \\
\hline Fast learning & $\begin{array}{l}\text { Lynn, Akgun, and Keskin } \\
\text { (2003) [22] }\end{array}$ \\
\hline $\begin{array}{l}\text { Learning faster and smarter to keep up with change, call } \\
\text { on new knowledge, and apply new skills }\end{array}$ & Landale (2004) [23] \\
\hline $\begin{array}{l}\text { Rapidized training; getting individuals to achieve high } \\
\text { levels of proficiency at a rate faster than ordinary; the idea } \\
\text { of making learning more immune to decay }\end{array}$ & Hoffman, et al. (2010) [13] \\
\hline
\end{tabular}

To accomplish this goal, we approached acceleration within our system in two ways:

1. Adapting the amount of content learners need to cover based on their current level of proficiency

2. Increasing the efficiency of the learning process

Our team is developing XL-CITR (Accelerated Learning for Cyber Insider Threat Reduction), a comprehensive training solution that integrates best practices in instructional design, competency-driven learning objectives, content filtering for accelerated learning, performance feedback, and learning management. The design of the study will be unique in that it will 1) be able to assess both the individual and the combined effects of learning acceleration and game-based interaction, and 2) incorporate objective psychophysiological measurements using principles of augmented cognition (e.g., real-time, unobtrusive, and quantitative measures). The focus of this paper is on our approach for measuring learner engagement. 


\section{Augmented Cognition}

A goal of augmented cognition research is to use psychophysiological measures such as electroencephalography (EEG), pupil diameter, and gaze tracking to identify-in real-time-perceptual, attentional, and cognitive workload states that may be helpful or detrimental to Warfighter performance [24]. Recent investigations within militaryrelevant training environments suggest that EEG signatures of attention, memory, and workload can be validly assessed during learning [25]. Furthermore, EEG measures offer a reliable means to accurately quantify key aspects of information processing [26] [27] [28]. These studies suggest that changes in EEG power spectra, as well as event-related EEG changes, are identifiable and correlate with levels of skill acquisition in simple and complex tasks. Thus, these measures are useful in matching mental capabilities to task and learning requirements so that mastery over the subject matter is maximized while mental effort is minimized [29].

The goal of the study run by augmented cognition researchers from the Interactive Simulation Laboratory ( $i$ Sim Lab) at the University of Alabama at Birmingham is to compare the cognitive state of learners who receive Accelerated Learning for Cyber Insider Threat Training (XL-CITR) training (e.g., fundamentals, quizzes, game-based interaction, and feedback) versus those who train using equivalent modules of a conventional training (CONVEN) implementation. An augmented cognition framework, using EEG and eye tracking sensors, will be used to assess the workload and the engagement levels of learners as they progress through abbreviated, generalized versions of XL-CITR and CONVEN, allowing design elements to be mapped onto intra- and inter-participant psychophysiological differences. That is, the experiment will establish individual baselines for the psychophysiological response measures and identify changes from baseline data during randomly assigned on-set and off-set exposure to the various program design elements. We expect the pattern of these changes in workload and engagement provide enough sensitivity to guide subsequent program and role-play game design.

\subsection{Equipment}

EEG. The wireless EEG sensor set to be used in this study was developed by Advanced Brain Monitoring (ABM). The system combines a $1.5 \mathrm{~V}$ battery-powered headset with a sensor placement system, following international standards. The full system is a lightweight, easy-to-apply cap that can acquire and analyze six to nine channels of high-quality EEG data. The sensors require no scalp preparation and provide a comfortable and secure sensor-scalp interface for 8 to 12 hours of continuous use. Sensor site locations on the system include the following: F3, F4, C3, C4, P3, P4, Fz, Cz, and POz. These sites can be combined in bi-polar or monopolar configurations (referenced to mastoids). The head pack contains miniaturized electronics that amplify, digitize, and transmit the EEG data in most environments, including environments with high electromagnetic interference.

Eye Tracking. Blink rate, pupil dilation, and scan path are convergent measures for mental workload [30]. The Arrington Research ViewPoint monocular eye tracker 
system will be used to track eye movements during the study. The eye tracker system uses an infrared (IR) light source to shine IR light on the eye, and the IR camera captures frames of images of eye as the person wearing the system performs different tasks, as shown in Figure 1. The eye camera and eye illuminator are located proximal to the eye; therefore, a head tracker is not required to accurately identify the pupil center. Using a bright pupil technique, the illuminator projects near-infrared light through the pupil such that the light reflects off the retina. The reflection created by the returning light traversing the cornea produces a bright pupil effect. This optical set-up allows the eye camera, which captures pictures of the eye every $17 \mathrm{~ms}(60 \mathrm{~Hz})$, to estimate the eye pupil center and to discriminate the corneal reflection (CR). These two parameters are then used to estimate the point of gaze of the operator. The accuracy of the point of gaze estimation by the Arrington eye tracker is less than 1 degree visual angle (roughly a $7 \mathrm{~mm}$ error when the participant is seated at $76 \mathrm{~cm}$ from the display, as in this study). Further, using the captured eye images, the image processing algorithms can distinguish between iris and pupil areas and fir a circle or ellipse to calculate pupil diameter in real-time.

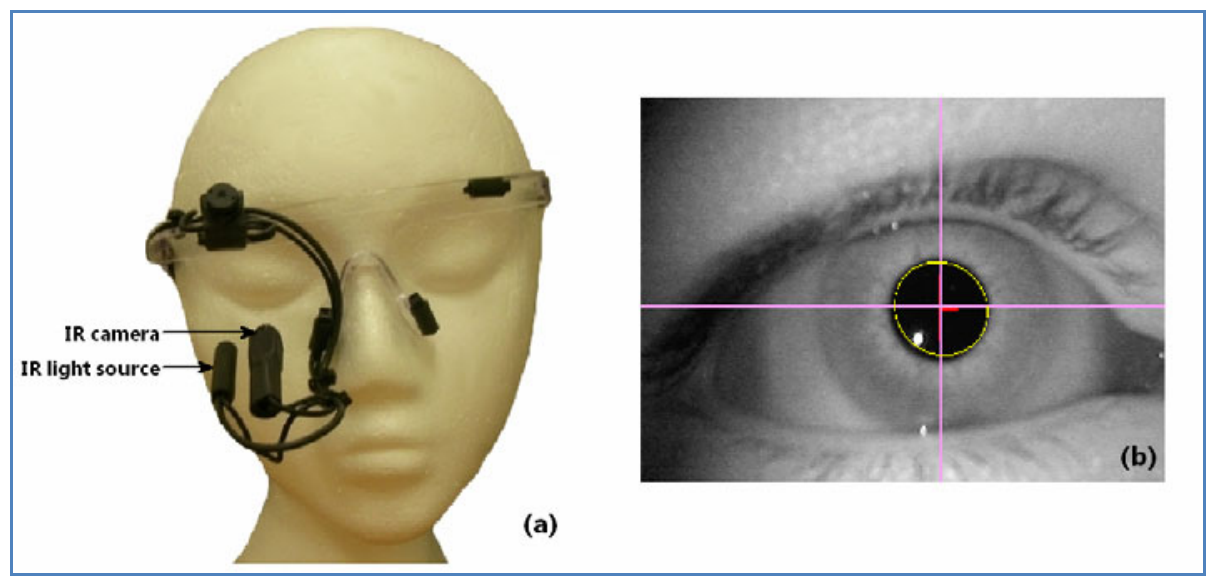

Fig. 1. (a) Arrington Research ViewPoint eye tracker system with infrared camera and light source. (b) Pupil detection using the light source and camera.

\subsection{Subjective Self-assessments}

An assessment of program quality and cognitive load surveys will be used in this study. Participants will respond twice, once for the XL-CITR module and once for the CONVEN module. These subjective measures should support the psychophysiological measures of workload.

\subsection{Participants}

A total of 32 male and female volunteer participants from the local military population (active duty, retired, or government-civilian) in Colorado Springs will participate in 
this study. Participants will be recruited through the local base newspapers and business groups. Participants in this study will have half of the training content delivered by the XL-CITR system and half by CONVEN. During the training, participants will wear a lightweight cap that will record psychophysiological measures as indicated in the equipment description Blink rate, pupil dilation, and scan path (of gaze) will be tracked with a remote camera.

\subsection{Method}

Participants will be fitted with the 9-channel, wireless EEG made by ABM. An impedance check of all sensors will then be performed. Once the sensors have settled to under $20 \mathrm{mV}$, a set of baseline tasks (a 3-choice vigilance task, an eyes-open rest task, and an eyes-closed task) will be performed to ensure that the EEG system is working properly. Once the EEG baseline is complete, the participant will undergo a calibration procedure to align the eye tracker coordinate system with that of the monitor displaying the XL-CITR content. In the calibration procedure, participants direct their gaze to 17 predefined points, one at a time, on the display, while the eye tracker maps the participants' eye position relative to the monitor.

Participants will be randomly assigned to one of four experimental conditions (GRP 1-4), balancing order of presentation and content set:

- GRP1: XL-CITR Module A, then conventional multi-media Module B

- GRP2: XL-CITR Module B, then conventional multi-media Module A

- GRP3: Conventional multi-media Module A, then XL-CITR Module B

- GRP4: Conventional multi-media Module B, then XL-CITR Module A

[The content of Module A will be the same across all conditions. The same holds true for the content of Module B.]

\subsection{Dependent Measures}

The dependent measures for this study include the EEG measures (EEG percent workload, EEG percent engagement, frequency changes at each EEG location, percent fixation for an area of interest), the eye tracking measures (blink rate, pupil diameter), subjective assessment of program quality, and the perceived workload based on the cognitive load questionnaire.

Testable Assumptions (TA) and Hypotheses (H)

- SII-TA1: The EEG measures of engagement will be sensitive enough to discern which aspects of the XL-CITR (e.g., fundamentals, quizzes, role-play game, and feedback) positively influence participants' focused attention.

- TA2: The EEG measures of workload will be sensitive enough to pinpoint such workload issues as how participants experience each component of the role-play game. As participants master the learning material, their workload will decrease while their performance will improve. 
- TA3: The blink rate and pupil dilation will provide a real-time convergent means to reinforce findings of the EEG measures. Those persons who master the task will make fewer saccades and more fixations toward relevant information.

- TA4: The cognitive load survey will provide an overall measure of cognitive workload that will assist in assessing the psychophysiological measures.

- H1: Average scores on psychophysiological measures of engagement: XL-CITR > CONVEN.

\section{Conclusion}

We believe new opportunities exist for researchers who want to quantify learner engagement and design environments that have a significant impact on learning performance. Our work in accelerated learning and learner engagement is just now examining a few of the many variables that might show a positive outcome. Future studies are planned to generate a set of best practices that can be adapted by large organizations who are interested in improving the overall learning experience for their workforce.

Acknowledgements. This material is based upon work supported by the Air Force Research Laboratory (AFRL) under Contract No. FA8650-10-C-6061. Any opinions, findings, conclusions, or recommendations expressed in this publication are those of the authors and do not necessarily reflect the views of AFRL.

\section{References}

1. Moe, T., Chubb, J.: Liberating learning: Technology, politics and the future of American education. Wiley, Hoboken (2009)

2. Jacobson, S.: Can we control training waster?. Frontline Magazine, 30-31 (March-April 2005)

3. Office of Management and the Budget. Report to Congress on the Implementation of the E-Government Act of 2002 (2005), Retrieved from http: / / www.whitehouse.gov/OMB/inforeg/2004_egov_report.pdf

4. Persaud, A.: A model of new product success and accelerated learning in collaborative new product team. Innovation: Management, Policy and Practice 6(2), 199-219 (2004)

5. Quinkert, K.A., Morrison, J.E., Fletcher, J.D., Moses, F.L., Roberts, E.J.: The Army Science of Learning Workshop. ARI Research Note 2007-02. Arlington, VA: US Army Research Institute for the Behavioral and Social Sciences (DTIC No. ADM001922) (2007)

6. Department of Defense. Department of Defense fiscal year (FY), budget estimate (2010), Retrieved from http: / / www. darpa.mil/Docs / 2010 PBDARPAMay2009.pdf

7. Randazzo, M.R., Keeney, M., Kowalski, E., Cappelli, D., Moore, A.: Insider Threat Study: Illicit Cyber Activity in the Banking and Finance Sector. National Threat Assessment Center, U.S. Secret Service, and CERT® Coordination Center/Software Engineering Institute, Carnegie Mellon (August 2004), Retrieved from http://www.secretservice.gov/ntac/its_report_040820.pdf

8. Bergeron, B.: Developing serious games. Charles River Media, Hingham (2005)

9. Fox, A.: The brain at work. HR Magazine 53(3), 36-43 (2008) 
10. Rock, D., Schwartz, J.: The neuroscience of leadership (2006), Retrieved from http: / /www.strategy-business.com/press/freearticle/06207

11. Rock, D., Schwartz, J.: Why neuroscience matters to executives (2007), Retrieved from http: / / www.strategy-business.com/li/leadingideas/li00021

12. Fidopiastis, C., Nicholson, D.: User-in-the-loop adaptive system design: Information fusion examples for visualizing and measuring cognitive states. In: Applied Ergonomics International Conference, Las Vegas, NV, July 14-17 (2008)

13. Hoffman, R.R.: Accelerated proficiency and facilitated retention: Recommendations based on an integration of research and findings from a working meeting. Report on Grant FA8650-09-2-6033, 1-352 (2010)

14. National Institute on Standards and Technology. Adaptive learning systems (2005), Retrieved from http://www.atp.nist.gov/atp/97wp-lt.htm

15. Orvis, K.A., Horn, D.B., Belanich, J.: Task difficulty and prior videogame experience: Their role in performance and motivation in instructional videogames. ARI Technical Report 1202. U.S. Army Research Institute for the Behavioral \& Social Sciences, Arlington, VA (June 2007)

16. Lozanov, G.: Suggestology and outlines of suggestodedy. Gordon and Breach Science Publishers, Inc., London (1978)

17. Gill, M.J., Meier, D.: Accelerated learning takes off. Training and Development Journal, 63-65 (1989)

18. Linksman, R.: How to learn anything quickly: An accelerated program for rapid learning. Citadel Press, Secaucus (1996)

19. Lawlor, M., Handley, P.: The creative trainer: Holistic facilitation skills for accelerated learning. McGraw-Hill, East Windsor (1996)

20. Rose, C., Nicholl, M.J.: Accelerated learning for the 21st century. Dell Publishing Group, New York (1997)

21. Russell, L.: Fortifying strategic decisions with shadow teams: A glance at product development. Competitive Intelligence Magazine 2, 9-11 (1999)

22. Lynn, G., Akgun, A.E., Keskin, H.: Accelerated learning in new product teams. European Journal of Innovation Management 6(4), 201-212 (2003)

23. Landale, A.: Mental agility training helps CSA staff to navigate rapid change. Human Resource Management International Digest 12(2), 20-23 (2004)

24. Schmorrow, D., Kruse, A.: Augmented cognition. In: Bainbridge, W.S. (ed.) Berkshire Encyclopedia of Human-Computer Interaction, vol. 1, pp. 54-59. Berkshire Publishing Group, Great Barrington (2004)

25. Berka, C., Levendowski, D., Lumicao, M., Yau, A., Davis, G., Zivkovic, V.: EEG correlates of task engagement and mental workload in vigilance, learning and memory tasks. Aviation Space and Environmental Medicine 78(5), pp. B231-B244 (2007)

26. Berka, C., Levendowski, D.J., Cvetinovic, M., Petrovic, M.M., Davis, G.F., Lumicao, M.N., Popovic, M.V., Zivkovic, V.T., Olmstead, R.E., Westbrook, P.: Real-time analysis of EEG indices of alertness, cognition and memory acquired with a wireless EEG headset. Special issue of the International Journal of Human-Computer Interaction on Augmented Cognition 17(2), 151-170 (2004)

27. Berka, C., Levendowski, D., Davis, G., Lumicao, M.N., Ramsey, C.K., Stanney, K., Reeves, L., Tremoulet, P.D., Regli, S.H.: EEG indices distinguish spatial and verbal working memory processing: Implications for real-time monitoring in a closed-loop tactical Tomahawk weapons simulation. In: Schmorrow, D. (ed.) Foundations of augmented cognition. Proceedings of the 1st International Conference on Augmented Cognition, pp. 405-413. Lawrence Erlbaum Associates, Mahwah (2005) 
28. Poythress, M., Russell, C., Siegel, S., Tremoulet, P.D., Craven, P.L., Berka, C., Levendowski, D.J., Chang, D., Baskin, A., Champney, R., Hale, K., Milham, L.: Correlation between expected workload and EEG indices of cognitive workload and task engagement. In: Proceedings of 2nd Annual Augmented Cognition International Conference, San Francisco, CA (2006)

29. Feldon, D.F.: The implications of research on expertise for curriculum and pedagogy. Educational Psychology Review 19(2), 91-110 (2007)

30. Sciarini, L.W., Fidopiastis, C., Nicholson, D.: Toward a modular cognitive state gauge: Assessing spatial ability utilization with multiple physiological measures. In: Proceedings of the 53rd Annual Conference of the Human Factors and Ergonomics Society, vol. 53(3), pp. 146-150. Human Factors and Ergonomics Society, Santa Monica (2009) 